\title{
Cine infantil: aproximación a una definición
}

\section{Children's Cinema: An Approach to a Definition}

María del Mar Rodríguez Rosell. Universidad Católica San Antonio

Irene Melgarejo Moreno. Universidad Católica San Antonio

Recibido: 20-XI-2009 - Aceptado: 18-XII-2009

Resumen:

La existencia de un conglomerado de teorías referentes al cine destinado para niños, junto a la diversidad de parámetros que giran en torno al cine infantil y a la falta de consenso entre autores a la hora de hablar de géneros cinematográficos -Sánchez Noriega (2002), Huerta Floriano (2005), Martínez Barnuevo (2008) ente otros-, nos hacen plantearnos una nueva revisión del cine para los más pequeños. De este modo, con una metodología de análisis puramente cualitativa, se aglutinan teorías y se aportan ideas, características y elementos que nos llevan a perfilar una definición lo más concreta posible de lo que hoy podemos denominar "Cine Infantil”.

Palabras clave: Cine Infantil, infancia, inteligencia fílmica, géneros, literatura.

Abstract:

The existence of several theories regarding children's movies, along with the diversity of parameters around films focused on children and the lack of consensus among authors about film genres -we mean experts as Sánchez Noriega (2002), Huerta Floriano (2005) and Martínez Barnuevo (2008), among others-a new dimension of cinema for this specific public is revised in this article. New theories, ideas, features and different elements can be showed through a purely qualitative methodology of analysis to outline the most specific definition of what we can define as "Children's Cinema" today.

Key Words:

Children's Cinema, Childhood, Film Intelligence, Genres, Literature. 


\section{Introducción}

Es de todos conocido que el Séptimo Arte nace como espectáculo que simplemente persigue el entretenimiento. Por ese motivo no es de extrañar que se encuentren desde los inicios del cinematógrafo producciones destinadas a los más pequeños que sirven para contentar su afán de diversión y para cubrir su siempre exigente tiempo de ocio. A lo largo de esos primeros años de vida del nuevo invento, se encuentran algunos productos llamativos de series como la de Mickey Mouse o las Silly Symphonies ${ }^{1}$, aunque es con la llegada del color cuando empieza a incrementarse el número de títulos dedicados a la infancia: Flowers and Trees (Disney, 1932) que pasa por ser el primer cortometraje de animación hecho con la técnica del Technicolor de tres componentes o Three Little Pigs (Disney, 1932) son sólo algunos ejemplos. Es a partir de 1937 cuando comienza una verdadera avalancha de largometrajes producidos por la conocida marca Disney, que se prolonga hasta nuestros días.

Lo cierto es que del cine infantil se habla poco aunque paradójicamente se ve mucho; al menos en los últimos años las grandes producciones realizadas para niños por las firmas más potentes de la cinematografía mundial, ésas hechas para la evasión y el ocio de los más pequeños, se encuentran entre las más vistas del año y han permitido que este tipo de cine se haya convertido en una parcela muy lucrativa para la industria cinematográfica ${ }^{2}$; con el fomento de la técnica 3D, los títulos infantiles se están multiplicando; no tenemos más que repasar títulos como Ice Age 3: el ocaso de los dinosaurios, Harry Potter: el misterio del príncipe, Los mundos de Coraline, UP, G-Force o Lluvia de albóndigas entre otros para comprobar que se ha dado lugar a historias especiales con otro punto de vista y una imagen casi envolvente, que acaricia y hace más partícipe al pequeño espectador. Personajes más realistas con escenarios tridimensionales que dan volumen a la imagen y que, sin duda, atraen a grandes cantidades de público a las salas cinematográficas. Cabe destacar el éxito del filme UP que consiguió más de cuatro millones de euros en el primer fin de semana del estreno convirtiéndose así en el mejor lanzamiento de un largometraje de animación en España³.

1 Serie de cortometrajes de animación producidos por Walt Disney en la década de los años treinta del pasado siglo (1929-1939) que a diferencia de las de Mickey Mouse, no usaba personajes continuos.

2 Es habitual encontrar películas de cine infantil entre los primeros puestos del ranking de recaudación: Kun Fu Panda, Wall-E o Madagascar: Escape 2 África entre las diez más vistas del 2008, Ratatouille o Shrek Tercero en el 2007, Ice Age: El Deshielo o Cars en el 2006. Incluso se cuelan en la lista de las diez que más han recaudado de la historia del cine películas como Harry Potter y la Piedra Filosofal (2001), Harry Potter y el Cáliz del Fuego (2005), Harry Potter y la Cámara Secreta (2002) o Buscando a Nemo (2003). Disponible en: http://www.imdb.com

3 En el día del estreno Up alcanzó una media por sala de 1.544€, superando los 1.287€ de Ice Age 3; Up logró salir con 105 copias más que cintas como Wall-E, gracias al atractivo formato 3D, que parece haber sido la clave del éxito. La película alcanzó los $400.000 €$ en las 141 copias en 3D, con una media por cine de 2.858€. Disponible en: http://www.boxoffice.es 
Desde el mundo científico son varios los autores que han reflexionado sobre los medios de comunicación y los niños o, de forma más concreta, sobre el cine dirigido a niños; cabe destacar Amelia Cano Calderón, Ana Díaz-Plaja Tabeada, Margarida Prats i Ripoll, José Ignacio Aguaded, Jacqueline Sánchez Carrero, M. ${ }^{\mathrm{a}}$ Luisa Martínez Barnuevo, José Luis Sánchez Noriega, Enrique Martínez-Salanova, Tomás de Andrés Tripero, Marta Roel Vecino, Jaime de Armiñán, Armand Mattelart, Ariel Dorfman o Nacho Jarne Esparcia entre otros. Y, sin embargo, desde un punto de vista teórico no parece que se llegue a un consenso claro que permita definir el cine infantil. Tal vez, el hecho de que los criterios para clasificar una película sean numerosos tenga la culpa, pero la cuestión es que no encontramos referencias claras que nos permitan estudiar de forma científica estos productos cinematográficos. Y entonces, ¿qué es el cine infantil? En algunos casos se habla de cine infantil como el que requiere de presencia de niños en la pantalla. En otras ocasiones, el cine infantil se confunde con el cine de animación ya que, en efecto, una gran cantidad de películas hechas con técnicas animadas se dirigen a un público infantil ${ }^{4}$, o incluso lo consideran como un género cinematográfico cuando en realidad no se trata sino de un cine realizado a través de una técnica determinada. Hay quienes piensan que una temática infantil es suficiente para que un largometraje sea clasificado dentro del cine infantil. Otros abogan por la calificación de edades a quien va dirigida...

El objetivo de este estudio es dar un nuevo paso que nos ayude a formular una definición concreta de cine infantil. Para ello, se revisa y se explica la evolución del concepto a lo largo del tiempo y se plantea la analogía entre literatura infantil y producciones cinematográficas atendiendo a tres nociones básicas: emisor, receptor y mensaje; por eso la intención del artículo se acerca al hecho de relacionar conceptos, ideas, características y elementos de este tipo de cine, y para ello será necesario el estudio de temáticas, personajes, argumentos o duración de los filmes entre otros elementos, ya que sólo así se podrán formular una serie de recomendaciones que nos acerquen a una definición acertada de este tipo de películas que podrían englobarse dentro de la denominación de "cine infantil”.

\section{Primeros encuentros de la infancia con los medios}

La infancia es una etapa concreta del desarrollo de todo ser humano, una realidad psicológica definida y basada -como afirma Debesse (1972) - en maneras idiosincrásicas de pensar, sentir y actuar, definida por la bondad y que requiere de un proceso educativo específico para poder fomentar sus potencialidades y re-

4 Un ejemplo reciente lo podemos encontrar en el libro El cine infantil de Hollywood escrito por Marcela Croce. (Editorial Alfama. Málaga, 2008) que intenta demostrar "el trasfondo ideológico que ha guiado al cine infantil de Hollywood en las últimas décadas", cuando las películas analizadas sólo incluyen cintas de cine de animación desde Aladdín hasta Bee Movie. 
cursos (De Andrés Tripero, 2006: 21). Es en esta etapa infantil, desde los 3 a los 6 años, cuando se origina el proceso de asimilación audiovisual por parte del menor que se completará hacia los 12 años con la denominada "Inteligencia Fílmica ${ }^{5}$ ". ¿Por qué consideramos la etapa infantil desde los 3 a los 6 años? Parece que los niños son cada vez más precoces tanto en la vida como en los aspectos audiovisuales, y que es en torno a los 9 años (y en algunos casos incluso menos) cuando sus inquietudes se distancian de lo puramente infantil cambiando sus intereses cinematográficos por completo. Sin embargo, antes de estar en plena posesión de esta capacidad, el menor se ve inmerso en toda una serie de fases mentales.

Cada vez más los niños entran en contacto con los medios de comunicación a una edad más temprana: podríamos decir que el primer contacto suele ser el televisivo y el cinematográfico (que se refiere al visionado de películas en DVD), pues el hogar se convierte en el lugar de iniciación audiovisual. Recordemos que en España casi el 25\% de los menores de 6 años comenzó a consumir televisión antes de los 2 años. Y el $40 \%$ lo hizo entre los 2 y los 3 años (Roel Vecino, 2007: 30). Algunos teóricos ya hablan de la formación de una "preinteligencia fílmica emocional y simbólica" a partir de los 2 años que se acentúa hasta los 6, pues la emoción se convierte en un elemento clave para el desarrollo de la inteligencia fílmica, como asegura De Andrés Tripero:

"La comprensión de las emociones del film no sólo favorecerá su específica inteligencia fílmica sino el resto, también, de sus capacidades intelectuales, afectivas y sociales” (De Andrés Tripero, 2006: 53).

Teóricos como Luria o Piaget han analizado el funcionamiento y evolución de la mente infantil que, como ya hemos comentado anteriormente, se caracteriza por la gran influencia lúdica y emocional. Si centramos nuestra atención en la relación entre el desarrollo del niño con lo cinematográfico, podríamos afirmar que durante la infancia, la imagen audiovisual cobra gran importancia y la comprensión de las películas se manifiesta a nivel psicológico de una forma particular. Por un lado, -afirma De Andrés Tripero-a los niños les cuesta establecer relaciones temporales entre las secuencias de un filme, por eso no entienden de forma clara la línea argumental o narrativa. Es frecuente que encuentren confusión entre la realidad y la ficción, que asimilen lo percibido y lo asocien con sus deseos y por último, que relacionen los contenidos y los significados en base a sus experiencias afectivas (De Andrés Tripero, 2006: 46-47).

\footnotetext{
5 De Andrés Tripero se refiere a la Inteligencia Fílmica como aquella que viene definida por 4 elementos del desarrollo intelectual de todo ser humano: la inteligencia lógica (comprensión de la estructura narrativa cinematográfica), la inteligencia de aprendizaje (recuerdo y asimilación), la inteligencia emocional (distinción de mensajes positivos y negativos) y la inteligencia moral (comprensión de valores y contravalores). De Andrés Tripero, Tomás: (2006). El desarrollo de la inteligencia fílmica. La comprensión audiovisual y su evolución en la infancia y adolescencia, CNICE, pp. 104-105.
} 
Teniendo en cuenta estos aspectos, se necesita de enseñanza previa, de un "rodaje dirigido", unos primeros pasos para conseguir una comprensión de los medios audiovisuales, de sus contenidos y de las diferentes formas con las que pueden representar la realidad, puesto que el entendimiento de los diferentes elementos audiovisuales no es algo innato en el ser humano, sino que se adquiere con el paso del tiempo. Los tres años parecen el momento idóneo para iniciar a los niños en el mundo perceptivo del cine; según MartínezSalanova,

"hay que comenzar viendo películas entretenidas, en cada edad las correspondientes. Lo lúdico y festivo es diferente en cada edad, cultura y condición” (Martínez-Salanova, 2002: 28).

\section{Analogía entre literatura y cine infantil}

Atendiendo a nuestro objetivo de encontrar una definición de cine infantil podríamos partir de un paralelismo con el mundo literario. De hecho, este tipo de cine se ha convertido a lo largo de los años en un auténtico vehículo de la literatura infantil que ha permitido llevar a la gran pantalla los cuentos tradicionales y las historias de niños y para niños. Porque, tal y como afirma Cano Calderón, la literatura infantil tiene mucha relación con el universo del cine infantil ${ }^{6}$.

García Padrino asegura que los problemas a la hora de delimitar el cine infantil son los mismos que los que aparecen para delimitar la literatura infantil y juvenil. No en vano, Ariel Dorfman y Armand Mattelart ya sostienen que los niños han sido gestados por una "literatura infantil y por las representaciones colectivas que la producen” (Dorfman y Mattelart, 2002: 37), mientras que Cano Calderón hablaba de las dificultades para el desarrollo de la literatura infantil, insistiendo en el hecho del límite difuso de las fronteras de este tipo de literatura y de las continuas discusiones sobre su contenido?

Otra forma de entender la literatura infantil podría ser aquella que está protagonizada por niños, aunque tal y como aseguran Ana Díaz-Plaja y Margarida Prats, los puntos de vista podrían ser variados al respecto. Para ellas la literatura infantil puede ser la literatura escrita por niños y, de hecho, esta consideración es bastante aceptada en el campo de la literatura dramática. También puede considerarse como la literatura

6 Amelia Cano afirma que "muchas de las cosas que se han dicho o escrito con relación a la literatura infantil entran de lleno y nos sirven para el mundo del cine infantil: la mirada del niño es distinta a la del adulto, el pensamiento del niño está repleto de artificialismo y de animismo, cualquier lectura (o visionado de película) va a servirle para desarrollar la imaginación y como evasión eliminando innumerables barreras" (Cano Calderón, 1993: 53-57).

7 La misma autora asegura que "uno de los elementos internos que más ha perturbado la buena marcha de la historia de la literatura infantil ha sido lo borroso de los contornos que delimitaban sus fronteras, esto es, qué contenido habría de tener, qué se consideraba literatura infantil y qué salía de su propio campo" (Cano Calderón, 1993: 54). 
protagonizada por niños o, en último caso, como la destinada a los niños como simples receptores. No obstante, tal y como critican algunos autores, las dos primeras nociones expuestas podrían ser discutibles: el hecho de que una obra esté escrita por un niño no tiene por qué significar que sea una obra dirigida a niños; de igual modo, una obra protagonizada por un niño no tiene por qué estar relacionada con la literatura infantil (Díaz-Plaja y Prats, 1998: 191).

Podríamos hablar, por tanto, de libros escritos por niños, libros que intencionadamente han sido escritos para niños, libros escogidos para niños (su inclusión viene determinada por revisores cualificados como críticos, profesores, etc.) y libros escogidos por niños (aquellos seleccionados y leídos por los niños aunque originalmente no hubieran sido pensados para ellos). De alguna manera estaríamos abordando la definición teniendo en cuenta tres criterios diferentes: el emisor, el receptor y el mensaje. Es decir, podríamos entender el término cine infantil desde el punto de vista del que lo ejecuta -si son niños los que realizan la producción cinematográfica-, del propio producto -que incluye imágenes o temáticas infantiles-, o desde el punto de vista del que lo recibe -si el espectador (entendido como espectador objetivo o no) es el niño.

\subsection{El emisor: el niño como creador}

La primera opción pasa por ser la menos habitual. Tal vez sea complicado hallar producciones cinematográficas profesionales realizadas por niños, y menos si nos referimos al ámbito nacional, aunque se pueden encontrar largometrajes de calidad como el filme El Guardavías (2006), primera película española realizada íntegramente por niños y adolescentes de la escuela de cine madrileña Orson The Kids, una organización que funciona desde el año 2000 como centro formativo dedicado a enseñar el cine a los niños y pre-adolescentes. Sin embargo, el hecho de estar realizada por niños no la convierte en una película de cine infantil, tal y como asegura su productor, el uruguayo Jorge Viroga: "La película tiene poco de infantil y nada que ver con el cine de niños, ellos ante todo son profesionales" ${ }^{8}$.

Aguaded Gómez y Sánchez Carrero encuentran experiencias similares en países como los Estados Unidos o Argentina. En el país norteamericano destaca el New York Film Academy, reconocida institución que desde edades tempranas admite alumnos que desean aprender a hacer películas y explorar la diversidad del medio cinematográfico. El Taller el Mate. Primera Escuela de Cine Infantil y Juvenil de Buenos Aires es otro centro creado en 1982 al que asisten niños desde los 9 hasta los 16 años de edad y cuyo principal fin es experimentar la realidad del proceso cinematográfico (Aguaded y Sánchez Carrero, 2008: 293-308). El "cine" que

8 Vid. "El Guardavías, el primer film hecho por niños, llega a los cines". Disponible en: http://laverdad.hoycinema.com/actualidad/noticias/CINE-ESTRENO-Guardavias-primer-film-hecho-por-ninos-llega-los-cines.htm. Consultado el 21/02/2006. 
resulte de estos talleres, cursos o escuelas podrá ser definido siempre como "cine hecho por niños", aunque no siempre como cine infantil, porque para poder ser definido como tal debe de contemplar además otros criterios. Volviendo sobre las ideas de Diaz-Plaja y Prats sobre la literatura infantil y juvenil, no habría inconveniente en incluir estas obras cinematográficas hechas por niños dentro del cine infantil, "siempre y cuando no se considere que éstas la definen en exclusividad” (Díaz-Plaja y Prats, 1998: 191).

\subsection{El mensaje: los atributos del producto cinematográfico}

Otro de los elementos a tener en cuenta para poder encontrar una definición de cine infantil pasa por explicar las características de los productos cinematográficos, atendiendo tanto a la forma como a la narrativa audiovisual de los mismos. Por eso, resultan fundamentales cuestiones tales como la técnica, la duración, los elementos acústicos y estéticos, las temáticas, los argumentos o los personajes.

\subsubsection{Aspectos formales}

Centrándonos en el tipo de producción según su técnica, tampoco se podría asegurar que todas las producciones realizadas con técnicas de animación pueden ser incluidas dentro del cine infantil. Tal y como apunta M. a Luisa Martínez Barnuevo la animación es "un modo de hacer películas y no un género. [...] está bastante claro que la animación puede abarcar cualquier género, tanto temática como estilísticamente" (Martínez Barnuevo, 2008: 53-54). Los dibujos animados (que se incluyen dentro del mundo de la animación pero que no la conforman en exclusiva) sí forman, sin embargo, parte de las técnicas favoritas de los más pequeños, sobre todo si su tratamiento es fluido y no presentan demasiados elementos acústicos o de color que les impresionen; así lo asegura el periodista valenciano José Moscardó Guillén:

"La verdad es que desde mediados de los años setenta del pasado siglo, ha desaparecido la idea de que las películas de animación son siempre para niños, aunque evidentemente son éstos los grandes consumidores de esta clase de películas, la mayoría de las cuales se realizan pensando en los más pequeños (muchas de las producciones Disney) o en los adolescentes (parte del fenómeno manga)” (Moscardó Guillén, 1997: 9).

Por otro lado, no parece demasiado sólida la idea de decidir clasificar películas como "de cine infantil" teniendo en cuenta la duración de las mismas. Aunque efectivamente la capacidad de atención limitada de los más pequeños convierte a los cortometrajes en el formato idóneo para estos textos cinematográficos, la verdad es que la mayoría de las películas infantiles tienen un formato de largometraje. Lo ideal, sobre todo si nos referimos al cine para menores de siete años, sería mostrarles varias sesiones de diferentes cortometrajes (lo más aconsejable son cortos de 10 ó 15 minutos), sin importarnos que las estructuras, los temas o los pequeños detalles entre ellos puedan resultar repetitivos, porque precisamente en la repetición casi 
idéntica de los relatos se basa el éxito de los cuentos infantiles. De los seis a los nueve años la película ya puede tener una duración de 30 a 45 minutos y de 90 a 100 cuando los niños tienen entre nueve y doce.

Dentro de los aspectos formales también deben de tenerse en cuenta los elementos acústicos y estéticos. Si nos referimos a la música, los niños gustan de la presencia de composiciones musicales entre sus producciones favoritas, mientras que si nos referimos a las voces, éstos prefieren las formas dialogadas frente a los comentarios de un narrador. Respecto a los aspectos estéticos, los más pequeños parece que admiran la belleza de los paisajes o los lugares exóticos con presencia de fauna viva.

\subsubsection{Aspectos narrativos}

Otro factor, tal vez más complejo, se refiere a la temática más utilizada en este tipo de producciones. Aunque se encuentran diferencias entre las favoritas por niños de uno u otro sexo, además de la comedia, los temas preferidos son las aventuras, la fantasía, los temas sentimentales (y no el tema amoroso que no parece interesar hasta la adolescencia), y los cuentos y leyendas; no en vano, el cine infantil se ha convertido durante años en un auténtico vehículo de la literatura infantil al trasladar a las pantallas cuentos tradicionales e historias de y para niños.

Los argumentos son otro de los aspectos a tener en cuenta si queremos definir las características del producto cinematográfico de cine infantil ideal. Por un lado, hasta los seis años se presta más atención a la sucesión de hechos que al propio argumento, por tanto la estructura de los mismos debe ser sencilla y lineal. Por otro lado, habría que cuidar la inclusión de elementos atemorizantes en los argumentos de las películas de cine infantil; en mayo del 2008 debería haberse estrenado la película de la Warner Bros Where the Wild Things Are, sin embargo, el largometraje creado a partir de elementos del mundo del miedo y del terror fue retirado tras los primeros pases de prueba con público, ya que provocaron "pavor y sollozos entre los niños asistentes". Tras esta reacción la compañía intentó suavizar el contenido pese a la oposición del director, aunque finalmente llegaron a un acuerdo en torno al montaje y las escenas que debían suprimir

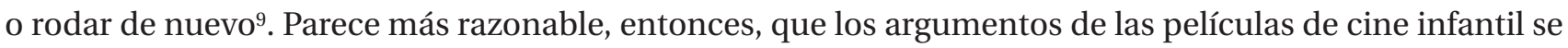
alejen de ese tipo de elementos que provocarían en los más pequeños un rechazo casi seguro. No obstante, hay quienes justifican la presencia de los mismos si el desenlace de la acción final desemboca en un resultado positivo para la historia.

Por último, entre los seis y los nueve años la acción debería integrarse en un argumento sólido que no se preste a la confusión y que evite las sucesiones de hechos secundarios y las largas descripciones; no olvi-

9 Vid. "Los monstruos del director Spike Jonze". Disponible en: http://www.20minutos.es/noticia/458662/0/spike/jonze/monstruos 
demos que es a partir de los nueve y hasta los doce años cuando los niños empiezan a interesarse por las biografías, los temas históricos, las películas documentales, la geografía o la naturaleza, entre otros.

Los personajes por los que muestran mayor interés son, por este orden: niños, animales (si éstos no son fieras peligrosas) y adultos. Entienden la presencia de "buenos" y “malos", aunque esperan que estos últimos sean castigados o ridiculizados en el caso de la comedia. En este aspecto, en una primera etapa infantil, los personajes desempeñan para los más pequeños el papel de juguetes pero con un alto grado de significación psicológica. Sin embargo, con el paso de los años, y conforme su desarrollo cognitivo es mayor, los personajes protagonistas son tomados como modelos de identificación, por ello los menores prefieren personajes que no se alejen demasiado de la realidad: "prefieren historias imaginativas, que se confunden en efecto con su propio imaginario, pero que tienen personajes realistas, naturales y verosímiles” (De Andrés Tripero, 2006: 48-50).

Nos gustaría detenernos en la figura del personaje principal, ya que no es difícil encontrar manuales que se refieran al cine infantil como aquel que incluye películas en las que los niños se convierten en los protagonistas: "Los numerosos filmes protagonizados por niños -o con peso de personajes infantiles en el repartosuelen encuadrarse dentro del llamado cine infantil o cine familiar de aventuras y entretenimiento [...]”, afirma Sánchez Noriega (2004: 296).

Son numerosas las producciones que podrían destacarse en las que se haya incluido algún tipo de representación de los niños: desde la fresca y espontánea infancia representada en El chico (1921) de Chaplin hasta la desgarradora visión de un grupo de niños en el remake de los años noventa de Harry Hook El señor de las moscas. Películas que indagan en la etapa infantil desde la ternura, desde las experiencias del aprendizaje o desde el punto de vista de aquel que sufre el abandono de los padres... Sánchez Noriega agrupa en su Diccionario temático del cine con acierto y bajo la entrada de "infancia”, algunas de las películas más importantes de la cinematografía mundial de todos los tiempos y propone diferentes clasificaciones: las de carácter autobiográfico de niños en todas sus vertientes (experiencias escolares, cambio a edad adulta, búsqueda del sentido de la vida, racismo, experiencia de la separación de los padres...); las de visión sufridora, pobre y de supervivencia (emigración, viajes, maltrato, discapacidad, explotación laboral o sexual...); las que relatan el enamoramiento infantil, el descubrimiento del sexo o las relaciones sexuales prematuras; las que se desarrollan en un contexto social bélico, etc. No obstante, deja fuera de esta clasificación aquella filmografía dedicada a niños prodigio ya que "sus personajes se alejan ostensiblemente del común de los niños” (Sánchez Noriega, 2004: 271) ${ }^{10}$. Sin embargo, la mayoría de estas películas no pueden ser considera-

10 Entre algunos de los títulos más famosos que podrían ser incluidos dentro de las clasificaciones expuestas se encuentran El limpia- 
das de cine infantil. El hecho de que sus protagonistas o sus guiones giren en torno a la figura de los más pequeños no las hace apropiadas para niños. ¿Acaso pensamos que El Bola (Achero Mañas, 2000) o Los niños de San Judas (Aisling Walsh, 2003) son largometrajes de cine infantil? Indiscutiblemente no; con sólo pensar en la violencia física y psicológica que se muestra de forma explícita en ellas podríamos entenderlo.

\subsection{El receptor: cualidades y finalidad}

Si nos centramos en el receptor, para poder encontrar los límites del cine infantil debemos tener en cuenta la capacidad de comprensión de los niños y hacer referencia a las edades que comprende la etapa de la infancia; algunos de estos aspectos han quedado perfilados en el segundo punto de este estudio bajo el título "Primeros encuentros de la infancia con los medios" en el que atendemos a la definición de infancia y al desarrollo en la inteligencia fílmica del menor. Basándose en esas características descritas algunos autores aseguran que las producciones infantiles, e incluso las juveniles, son las idóneas para este tipo de público porque consiguen adecuarse a los conocimientos y percepciones de los más pequeños; de este modo, tal y como afirman Cary Bazalgette y David Buckingham, el espectador aparece como variable objetiva para definir un tipo de cine: "Children's films can be defined as offering mainly or entirely a child's point of view" (Bazalguete y Buckingham, 1995: 96).

Rodríguez Rosell atendiendo a las características del espectador y al desarrollo intelectual y emocional de los menores, piensa que el emisor debería producir películas pensadas especialmente para la infancia y definidas en su totalidad para que puedan ser englobadas dentro del que puede denominarse como cine infantil. Así, debería adaptar los aspectos narrativos y técnicos del filme a las capacidades de comprensión y conocimientos de un receptor niño, con el fin de que la producción cinematográfica pueda cumplir las funciones de diversión, entretenimiento y educación para no olvidar los aspectos sociales, educativos y empáticos de este medio (Rodríguez Rosell, 2007: 46).

Sanchez Noriega, partiendo de la base de la importancia de definir el cine infantil desde el punto de vista de la finalidad o la recepción, aborda la definición del mismo apoyándose en las categorías supragenéticas que se explican teniendo en cuenta variados y diferentes elementos. Estas categorías, que tienen que ver con los procesos de creación más importantes para el resultado estético del filme, atienden a aspectos acceso-

botas (Vittorio de Sicca, 1946), Los cuatrocientos golpes (François Truffaut, 1959), El Milagro de Ana Sullivan (Arthur Penn, 1962), El espíritu de la colmena (Víctor Erice, 1973), La guerra de papá (Antonio Mercero, 1977), Fanny y Alexander (Ingmar Bergman, 1982), El imperio del sol (Steven Spielberg, 1987), Secretos del Corazón (Montxo Armendáriz, 1987), Mi chica (Howard Zieff, 1991), En busca de Bobby Fischer (Steve Zaillan, 1993), El Bola (Achero Mañas, 2000). 
rios de los textos fílmicos como la producción, el origen o la finalidad, o bien aquellos criterios ligados a la forma externa de los mismos como la duración o la estructura. Es por eso que el autor considera al cine infantil como una categoría supragenética, aunque esta definición no excluya otro tipo de clasificaciones en base a formatos, géneros, especializaciones, ciclos o subgéneros (Sánchez Noriega, 2002: 97). Lo que parece evidente es que dentro de esta tela de araña de conceptos y clasificaciones que propone Noriega, el cine infantil puede ser definido en base a la recepción del mismo, teniendo en cuenta su finalidad y las características de su público objetivo. Aunque también deban contemplarse otro tipo de variables como la calificación por edades para definir y clasificar los textos fílmicos.

La edad genera numerosas diferencias en las clasificaciones dependiendo de si nos referimos a ella como base para explicar aspectos médicos, psicológicos, jurídicos, etc... Jaime de Armiñán, reconocido director y cineasta español, aboga por las características del receptor para definir el cine infantil, ya que asegura que: "hablar de cine infantil es referirse a niños de muy corta edad, porque ahora los que tienen más de nueve prefieren las de sexo y violencia" (De Armiñán, 1995). Sin embargo, no es arriesgado afirmar que la gran mayoría de clasificaciones por edad tienen que ver de alguna forma con la teoría del desarrollo evolutivo de Piaget, en la que el desarrollo intelectual está claramente relacionado con el desarrollo biológico. Como recoge la Enciclopedia GER, las diferencias en el desarrollo intelectual de los niños hace complicada la tarea de marcar categorías limitadas de edad, aunque sí podrían formarse dos grandes grupos específicos: los niños menores de 7 años y los niños entre los $7 / 8$ años hasta los 12/14 en la que tendríamos que situar la barrera del cine juvenil.

Los expertos sostienen que los más pequeños, los menores de 7 años, deben ver cine especialmente pensado para ellos, un cine que se adecúe a su mentalidad fácilmente impresionable, que tenga en cuenta tanto su falta de capacidad para distinguir lo real y lo imaginario como la dificultad que presentan a la hora de fijar la atención, sobre todo durante periodos de tiempo largos (GER, 1991). Y es que la recepción y decodificación de las imágenes para el niño en proceso de formación no están tan claras como podemos llegar a pensar; no debemos olvidar que el cine es capaz de impactar emocionalmente a los más pequeños que no son capaces de interiorizar ni entender el verdadero significado de lo que reciben en la gran pantalla. Teniendo en cuenta que las condiciones de la edad y el grado y nivel de formación del individuo condicionan el sentido y el significado de la imagen como significante, entre los 8 y los 12 años el niño puede recibir cualquier tipo de texto audiovisual siempre y cuando tenga contenidos adecuados y no incluya temáticas sexuales o violencia. 
Desde un punto de vista técnico, también las edades pueden suponer un problema para entender con claridad los mensajes audiovisuales, ya que no es hasta los 12 ó 14 años cuando se va reforzando y afianzando la comprensión del lenguaje cinematográfico en su conjunto.

Lejos del desarrollo biológico aunque también relacionado con la edad de los receptores, encontramos categorías a la hora de calificar películas para determinados públicos. En el caso español las obras cinematográficas están calificadas por el ICAA (Instituto de Cinematografía y Artes Audiovisuales) o por el órgano competente de la comunidad autónoma atendiendo a los siguientes criterios: especialmente recomendada para la infancia, para todos los públicos, no recomendada para menos de siete años, no recomendada para menos de trece años, no recomendada para menores de dieciocho años y películas $\mathrm{X}$ (Real Decreto 2062: 2008) ${ }^{11}$. El director del ICAA es, según la legislación, el responsable de firmar la resolución que califica a cada largometraje tras leer el informe escrito por la Comisión de Calificación que él mismo nombra. Y como puede observarse, los grupos de edad predefinidos para calificar las películas -sobre todo de niños- no coinciden exactamente con los expuestos anteriormente y que se refieren al desarrollo intelectual de los mismos.

A partir de estos tres criterios -desarrollo intelectual y emocional de los menores, categorías supragenéticas y edad-, que pueden ayudar a entender el cine infantil desde diferentes puntos de vista, encontramos otros autores que basan su definición en aspectos mixtos que tendrían en cuenta además del propio receptor, elementos tales como las características del mensaje, la temática, la técnica o el entretenimiento entre otras. Así, el profesor Paul Wells, tal y como recoge Martínez Barnuevo, aborda los géneros desde diferentes puntos de vista, y por eso insiste en las normas de estilo, los códigos específicos o los argumentos como las claves para definirlos (Martínez Barnuevo, 2008: 53).

Como puede comprobarse con la gran cantidad de referencias incluidas, no es fácil encontrar definiciones que den una respuesta clara o concisa a esta cuestión, y la maraña teórica que se ha generado alrededor de los tipos de textos fílmicos es evidente. Sin embargo, una posición reforzada aparece cuando nos referimos al cine infantil como género cinematográfico; Sánchez Noriega reconoce que lo más habitual es hablar de géneros, aunque también insiste en no perder de vista otro tipo de clasificaciones que podrían ayudar a definirlos (Sánchez Noriega, 2002: 96). Así pues, podríamos atender a clasificaciones que tengan en cuenta el

11 El 19 de febrero de 2010 se publica en el BOE la Resolución del Instituto de Cinematografía y de las Artes Audiovisuales, por la que se establecen nuevos criterios para la calificación por grupos de edad de las películas cinematográficas y otras audiovisuales, así como pictogramas informativos. Los grupos de edad quedan como sigue: "Apta para todos los públicos"; "No recomendada para menores de siete años"; "Especialmente recomendada para la infancia”; "No recomendada para menores de doce años"; "No recomendada para menores de dieciséis años"; "No recomendado para menores de dieciocho años"; y "Película X". 
formato de la película, su duración, su finalidad, su estilo, la materia audiovisual, el tipo de producción, la estructura, el origen del guión o el público al que se dirigen.

Efectivamente, algunos de estos aspectos pueden ayudarnos a clasificar las películas en determinados formatos, categorías o géneros cinematográficos (Sánchez Noriega, 2002:97). El debate sobre los géneros cinematográficos continúa abierto porque "los géneros están en permanente evolución, se transmutan según avanza el tiempo, se modifican en función de los intereses que lo circundan” (Huerta Floriano, 2005: 353). Pensemos que para definirlos deberíamos atender a criterios variados que tengan que ver no sólo con una cuestión textual del documento cinematográfico (cuestiones estéticas, narrativas o de contenido), sino con aspectos industriales, críticos, socioculturales e incluso institucionales.

\section{A modo de conclusión: una posible definición de cine infantil}

El proceso de comunicación cinematográfico se entiende, dentro de las teorías de la comunicación, como una estructura sencilla (emisor-mensaje-receptor), que parte de una emisión dirigida del mensaje a través de un canal y que se cierra en la recepción. En el caso del cine infantil, el emisor no parece condicionar la definición del mismo, ya que la edad del autor del producto no es determinante para clasificar la cinta dentro de esta denominación. Sería discutible dar cabida al canal como elemento preciso de este tipo de cine, ya que la recepción en sala cinematográfica o en el hogar, aun siendo muy diferentes, no varía la esencia del producto, aunque puede condicionarla. El cine infantil, por lo tanto, se define teniendo en cuenta dos variables: el receptor y el propio mensaje.

Si hablamos del primero, el que se refiere al receptor, deberíamos de tener en cuenta cuestiones como la finalidad, aunque entre las variadas características del receptor es la edad la que incidirá posteriormente en el grado de desarrollo de la inteligencia fílmica, así como en su capacidad cognitiva. En este sentido, el cine infantil considera a sus receptores, por las características descritas, a los niños de entre 3 y 6 años, y es dentro de esa horquilla de edades en la que delimitamos los productos de cine infantil.

Si hablamos del segundo, el que se refiere al mensaje, el producto cinematográfico deberá atender a dos aspectos: formales y narrativos. Se recomienda que la duración de una película infantil sea de 10 a 15 minutos; si tuviéramos en cuenta este dato sería muy difícil encontrar ejemplos más allá de los puros cortometrajes, por tanto lo importante sería que en la duración total de una película se pudieran encontrar bloques de desarrollo narrativo de 15 minutos que, sumados, configuraran la historia en su conjunto, haciendo que el infante no perdiera la atención aunque la duración fuera más larga de lo que a priori se recomienda para 
su edad. Más allá de la duración, caracterizan también a estas producciones desde un punto de vista formal, la presencia de elementos como músicas pegadizas y rítmicas, formas dialogadas simples e historias desarrolladas con una puesta en escena basada en ambientes reconocibles y familiares para el menor.

Un aspecto que no define al cine infantil es la técnica empleada, aunque bien es cierto que la técnica de dibujos animados, de animación por ordenador o de 3D aparecen tradicionalmente ligadas al mundo de los más pequeños. Pero los aspectos narrativos del mensaje también forman parte de la propia definición. Así, las temáticas más comunes serían la comedia, la aventura, la fantasía y las cuestiones sentimentales, además de la adaptación audiovisual de cuentos y leyendas tradicionalmente literarios.

Sumado a la importancia de la temática aparecen también los argumentos como elemento definitorio de cine infantil. Estos deben alejarse de elementos relacionados con el miedo y el terror, y en todo caso atender a una estructura lineal clásica y simple -planteamiento, nudo y desenlace- como la de los cuentos tradicionales, ya que son las más adecuadas para la comprensión de los niños de la edad definida anteriormente.

Por último, los personajes se unen a esta lista de elementos que configuran la definición de cine infantil. Los menores gustan de personajes reales que pueden ser niños, animales (siempre y cuándo no sean peligrosos) o adultos, y entienden el binomio bondad/maldad como cualidades de los mismos siempre y cuando lo malicioso venga acompañado de un castigo final.

\section{Referencias bibliográficas}

Aguaded Gómez, J. I. y Sánchez Carrero, J. (2008): "Niños y adolescentes tras el visor de la cámara: experiencias de alfabetización audiovisual”, Estudios sobre el Mensaje Periodístico, n. 14, pp. 293-308.

Bazalgette, C y Buckingham, D. (1995): In front of the Children. Screen entertainment and young audiences, British Film Institute.

Cano Calderón, A. (1993): “El cine para niños, un capítulo de la literatura infantil”, Revista Interuniversitaria de Formación del Profesorado, n. 18, pp. 53-57.

Croce, M. (2008): El cine infantil de Hollywood. Una pedagogía fílmica del sistema político metropolitano, Málaga: Alfama.

De Andrés Tripero. T. (2006): El desarrollo de la inteligencia fílmica. La comprensión audiovisual y su evolución en la infancia y adolescencia, CNICE, Ministerio de Educación y Ciencia.

Díaz-Plaja Tabeada, A. Prats y Ripoll, M. (1998): “Literatura infantil y juvenil”, en Mendoza Fillola, Antonio (coord.): Conceptos clave en didáctica de la lengua y la literatura, Foreing Language Study, pp. 191-214. 
Dorfman, A. y Mattelart, A. (2002): Para leer al Pato Donald, Buenos Aires: Siglo XXI.

Huerta Floriano. M. A. (2005): Los géneros cinematográficos: usos en el cine español (1994-1999), Salamanca: Publicaciones Universidad Pontificia de Salamanca.

Jarne Esparcia, N.: "Animación, animation, anime", Cuadernos de cine y educación. Revista Digital Making Of del Centro de Educación y Pedagogía, disponible en: http://www.comunicacionypedagogia.com/publi/emo/revista/pdf/59/introanimacion.pdf p. 6. Consultado el 12/03/2009.

Martínez Barnuevo, M. L. (2008): El largometraje de animación español: análisis y evaluación, Madrid: Ediciones y Publicaciones Autor.

Martínez-Salanova, E. (2002): Aprender con el cine, aprender de película. Una visión didáctica para aprender e investigar con el cine, Huelva: Grupo Comunicar.

Moscardó Guillén, J. (1997): El cine de animación en más de 100 largometrajes, Madrid: Alianza Editorial.

Rodríguez Rosell, M. M. (2007): “En el nombre del cine”, en Merayo Pérez, Arturo (ed.): El gato en el microondas. Enseña a tu hijo a convivir con los medios, Barcelona: Nabla Ediciones, pp. 45- 64.

Roel Vecino, M. (2007): “Érase una vez la televisión...”, en Merayo Pérez, Arturo (ed.): El gato en el microondas. Enseña a tu hijo a convivir con los medios, Barcelona: Nabla Ediciones, pp. 15-43.

Sánchez Carrero, J. (2008): Pequeños directores: niños y adolescentes creadores de cine, vídeo y televisión. Un recorrido por experiencias reales de alfabetización audiovisual: de la producción a la lectura crítica, Sevilla: Aconcagua Libros.

Sánchez Noriega. J. L. (2002): Historia del Cine. Teoría y géneros cinematográficos, fotografía y televisión, Madrid: Alianza Editorial.

Sánchez Noriega. J. L. (2004): Diccionario temático del cine, Madrid: Cátedra.

\section{Referencias electrónicas}

"El Guardavías, el primer film hecho por niños, llega a los cines" (2006). Disponible en: http://laverdad.hoycinema.com/actualidad/noticias/CINE-ESTRENO-Guardavias-primer-film-hecho-por-ninos-llega-los-cines.htm. Consultado el 12/03/2009.

Gran Enciclopedia Rialp (1991). Disponible en: http://canalsocial.net/GER/ficha_GER.asp?id=3636\&cat=arte. Consultado el 11/03/2009.

"Los monstruos del director Spike Jonze" (2009). Disponible en: http://www.20minutos.es/noticia(458662/0/spike/jonze/ monstruos. Consultado el 26/03/2009.

Real Decreto 2062/2008, de 12 de diciembre, por el que se desarrolla la Ley 55/2007, de 28 de diciembre, del Cine. Disponible en: http://www.boe.es/boe/dias/2009/01/12/pdfs/BOE-A-2009-503.pdf. Consultado el 15/03/2009

The Internet Movie Database: http://www.imdb.com 